\title{
Patterns in the appropriation of a learning management system by instructors based on Q-methodology
}

\section{Daniel Ebbert}

\section{Correspondence:}

daniel.ebbert@uni-muenster.de Westfälische Wilhelms-Universität Münster / University of Twente, Full list of author information is available at the end of the article

\begin{abstract}
Learning management systems are widely used and their adoption and usage is well researched. However, most of the research about learning management systems is based on technology acceptance models which do not include the users appropriation. Appropriation of learning management systems is understood as the combination of functionalities within the learning management system for new purposes. To study which functionalities are perceived as important by the instructors Q-methodology has been applied. The items for the Q-set are the functionalities of the learning management system. The result is that there are three factors. These are the usage of the learning management system for (1) convenience, for (2) tracking the progress of the students and for (3) facilitating student interaction.
\end{abstract}

Keywords: Q-methodology; e-learning; learning management systems; Moodle; course design; appropriation

\section{Introduction}

Learning management systems (LMSs) are widely used at universities to provide e-learning (Torrisi-Steele and Drew, 2013) and their main function is to process, store, and distribute educational material as well as to support the administration and the communication associated with teaching and learning (McGill and Klobas, 2009). The two LMSs with the biggest market share are Blackboard and Moodle (Green, 2013). The adoption and usage of LMSs is well researched, usually based on technology acceptance models. However, technology acceptance models are missing the users' appropriation of the technology (Salovaara and Tamminen, 2009), in this case that means how instructors combine the functionalities they could use.

The LMS used at the University of Münster is Moodle. It has been used since 2005. Historically there have been multiple LMSs at the University of Münster and Moodle is the LMS that prevailed and is now the most used LMS. Central to the usage of LMSs is the concept of courses which can be created using the functionalities the LMS provides. The term course refers to a separate section within the LMS that the instructors can use to support a lecture or seminar. The usage of the LMS by the instructors is voluntarily and the instructors have to manually request courses at the beginning of every semester.

In the context of LMS usage appropriation is to combine the provided functionalities to create a course. Thus, LMSs are created to be appropriated. This study is exploratory and discusses the appropriation of an LMS by instructors for the 
purpose of creating a course. Considering that there always are multiple ways of appropriating a technology there also will be multiple ways in which instructors create their courses. Thus, a method is needed which is suited for distinguishing groups of participants.

As the appropriation of the LMS is the combination of its functionalities to create a course, a sorting method is needed as it allows the participants to sort the functionalies based on importance. Q-methodology (Stephenson, 1953) has been chosen as it is uniquely suited for the purpose of identifying patterns of usage by using functionalities as sorting items.

\section{Research Questions}

Based on the assumption that studying the usage and appropriation of an LMS from the instructors perspective might be of interest the research question is:

$R Q 1$ Are there patterns in the appropriation of a learning management system by instructors?

\section{Related Work}

The related work covers the use of LMSs and factors related to the adoption and usage of these systems as well as an elaboration of the concept of appropriation.

\section{Learning Management Systems}

LMSs are created to enable instructors to use e-learning activities like evaluating students, presenting information and managing learning materials (Yueh and Hsu, 2008). Thus, LMSs can be used to supplement traditional teaching or to facilitate distance learning (Al-Busaidi and Al-Shihi, 2012). Whether a LMS is used and which LMS is used is sometimes mandated by the university and sometimes the faculties are allowed to choose their own LMS. However, even if the adoption is mandatory, the level of usage varies (Sinclair and Aho, 2017).

A good example for a study on the adoption and usage of a LMS is Motaghian, Hassanzadeh, and Moghadam (2013) who, based on the technology acceptance model (TAM) (Davis, 1989), state that perceived usefulness is the most influential factor for adoption of an LMS while Šumak, Polančič, and Heričko (2010) based on the unified theory of acceptance and use of technology (UTAUT) (Venkatesh et al., 2003), conclude that the performance expectancy and social influence have a significant impact on the attitudes towards the LMS. Furthermore, Raman and Don (2013) confirmed the use of the extension of the unified theory of acceptance and use of technology (UTAUT2) for the context of LMS usage and state that performance expectancy and effort expectancy have impact on the behavioral intention. As these example studies and the overview by Hew and Syed Abdul Kadir (2016) show, studies on the adoption and usage of LMSs are usually based on TAM, UTAUT, UTAUT2 or variants of these. The key concepts of theses models are perceived usefulness, performance expectancy, perceived ease-of-use, and effort expectancy.

However, the fact that these LMS studies are based on technology acceptance models means that Salovaara and Tamminen's (2009) critique on technology acceptance models applies. Salovaara and Tamminen (2009) state that technology acceptance 
models can lead to the assumption that every user uses technology in the same way, which does not account for users using a product in different ways. That users can invent new uses for a technology is called appropriation.

\section{Appropriation}

Appropriation is defined as:

... the way in which technologies are adopted, adapted and incorporated into working practice. This might involve customisation in the traditional sense (that is, the explicit reconfiguration of the technology in order to suit local needs), but it might also simply involve making use of the technology for purposes beyond those for which it was originally designed, or to serve new ends. (Dourish, 2003)

Thus, appropriation is the usage of a technology in a way that is creative or unusual, like using a camera as a mirror or scanner (Salovaara et al., 2011). Appropriable technologies can be described in three ways (Salovaara, 2007), these are as configurational (Williams et al., 2005), equivocal (Huysman et al., 2003), or user-tailorable (MacLean et al., 1990). LMSs can be described along all three characteristics. They are configurational in the way that a course in an LMS can be configured or designed by using the single components that are available to create something new. 'Pick and mix' is possible (Williams et al., 2005). Furthermore, LMSs are equivocal, or in other words an open-ended technology (Weick, 1990). Equivoque technologies offer many possible and plausible interpretations (Weick, 1990). Lastly, LMSs can also be described as user-tailorable, which is described as a system which allows the end users, in this case the instructors, to tailor the system to their needs (MacLean et al., 1990). Thus, LMSs allow multiple viewpoints on information, which is an important feature of appropriable technologies according to Dourish (2003). Thus, the appropriation of an LMS is to combine the provided functionalities to create a course, which is a form of 'pick and mix' (Williams et al., 2005).

However, knowing that a technology will be appropriated and designing for appropriation are two separate concerns. The guidelines for designing for appropriation are to: (1) allow interpretation, (2) provide visibility, (3) expose intentions, (4) support not control, (5) plugability and configuration, (6) encourage sharing and (7) learn from appropriation (Dix, 2007). Especially the appropriation guidelines of (4) support not control and (5) plugability and configuration (Dix, 2007) are of relevance and can be applied to the creating of a course in an LMS as a LMS supports the users in fulfilling different tasks with their course content, which can be plugged together in different ways. Furthermore, the functionalities to be used in an LMS course can also be extended by means of changing existing or adding new functionalities, a feature that the LMS market leaders support. This fulfills the guideline of (7) learning from appropriation (Dix, 2007). This means that LMSs are made to be appropriated. Therefore, studying the course design within an LMS might lead to interesting results that could be used to improve how LMSs are being used.

Studying the course design within an LMS can be approached in multiple ways. One such way would be to approach it from a perspective of data mining as it has been done by Whitmer (2016). Whitmer (2016) analyzed patterns in the course design to determine how instructors actually use the LMS by studying 70000 courses 
using Blackboard Learn. This resulted in five course archetypes, these are: (1) supplemental, (2) complementry, (3) social, (4) evaluative and (5) holistic. The supplemental archetype has lots of content and hardly any student interaction, the complementary archetype is mainly used for communication from the instructor towards the students, the social archetype has lots peer-to-peer interaction, the evaluative archetype heavily uses assessments and the holistic archetype balances the content, interaction, and assessments (Whitmer, 2016).

These are interesting results, but they exclude the possibility that a functionality that is used once might be as important to the instructor as a functionality which has been used multiple times. An example of this could be that an instructor uses a functionality that divides students into groups in the beginning of the semester and afterwards provides multiple assignments by group. In this case the functionality for dividing the students into groups could be as important to the instructor than the possibility to provide assignments, although the functionality to provide assignments has been used multiple times while the functionality to divide the students into groups has only been used once. To determine these differences a research method is needed that focuses on the instructors perception rather than their activity usage frequency in the LMS.

\section{Methods}

The objective is to study the perceived importance of functionalities by instructors for the design of their course in the LMS. For this purpose Q-methodology, which is a sorting method, has been chosen. In order to gain more information to aid the factor interpretation a pre-sorting questionnaire as well as a post-sorting interview has been conducted.

\section{Q-methodology}

While using sorting methods the participants are presented with a set of objects to divide in groups and afterwards sort along a distribution (Coxon, 2004). The sorting method chosen for this study is Q-methodology (Stephenson, 1953), as it provides an opportunity to distinguish groups within the population (ten Klooster et al., 2008). Q-methodology is most commonly used to measure subjectivity by ranking a set of statements along a distribution (Brown, 2004). However, it is not limited to this and can be applied in different contexts and with different sorting items (Watts and Stenner, 2012). The two main features that are characteristic to studies using Q-methodology are (1) the collection of data in the form of a Q-sort, which is a way of sorting the cards along a distribution and (2) the intercorrelation and by-person analysis of these Q-sorts (Watts and Stenner, 2012). Q-methodology has also been called an inverted technique of factor analysis (ten Klooster et al., 2008) because the participants are correlated instead of the items. The analysis can be done by either using centroid factor analysis or principal component analysis (PCA), which in practice result in very similar results (Watts and Stenner, 2012).

Q-set design

The process of creating a Q-set consists of two steps: (1) building up a concourse and (2) drawing the $\mathrm{Q}$-set from that concourse. 
Concourse The concourse consisted of two kinds of items: normal functionalities of the LMS and appropriations of these functionalities. The appropriations of these functionalities have been determined in a small pre-study which consisted of interviewing 12 users of the LMS and analysing the templates of the database function. Each item in the concourse consisted of the name of the functionality followed by a short description. The concourse consisted of the 34 functionalities available to lecturers within the LMS plus 12 appropriations that have been added based on the pre-study. This resulted in a concourse of 46 items.

Q-set The Q-set has been drawn from the concourse using exclusion criteria. Functionalities that require external tools and specialized knowledge have been excluded as well as the functionality of accessing course statistics as it does not directly influence the course design. This resulted in a Q-set of 41 items. The full Q-set is provided in appendix A, this consists of the handle, name and description of each item. The items are referred to by their handles.

\section{Distribution}

For this study a fixed distribution has been chosen because a free distribution does not provide additional information and the fixed distribution has the advantage of providing the data in a convenient and readily processed form (Block, 2008). The participants sorted the items along a distribution from unimportant (-5) to important $(+5)$ for their chosen reference course, the used distribution is shown in figure 1.

\section{Pre-sorting questionnaire}

In the pre-sorting questionnaire demographic data about the participants has been collected as well as information concerning their usage of the LMS and the specific course chosen by the participants for the purpose of this study. The demographic data collected about the participants consists of their gender, age, which faculty they belong to, which position they have, how many hours a week they are teaching, and of how much experience they have using Moodle or other LMSs. To gain more background information about the participants a pre-sorting questionnaire was created which consisted of a self developed scale for digital skills which was inspired by the knowledge domain of Ritzhaupt and Martin (2014), the personal innovativeness scale by Agarwal and Prasad (1998), the user interface scale by Cho,

Figure 1 The used distribution for the Q-sort.

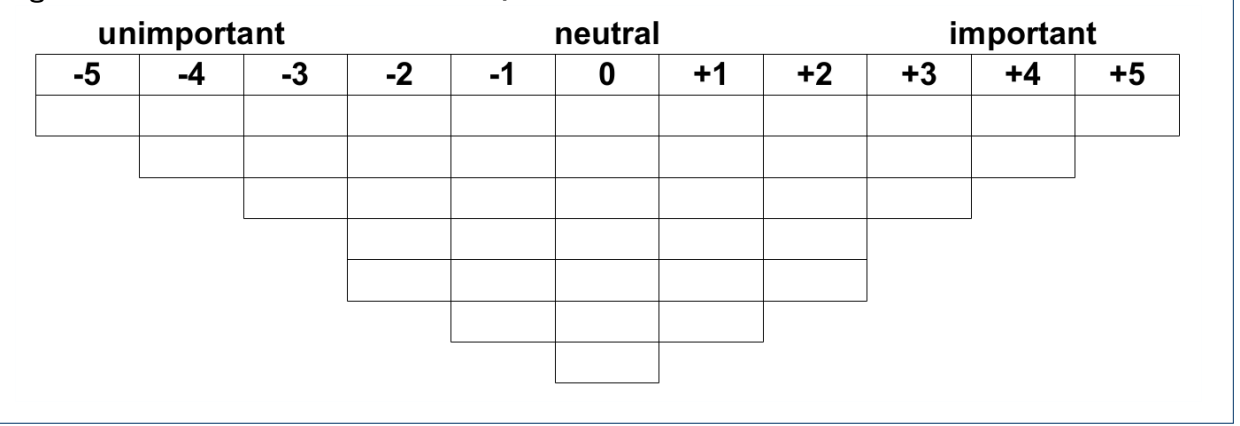


Cheng and Lai (2009), the perceived usefulness scale by Sørebø and Sørebø (2008), and the user satisfaction scale by Mouakket and Bettayeb (2015). The demographic data as well as the digital skills scale has been summarized. For the scales of personal innovativeness, user interface, perceived usefulness and user satisfaction Cronbach's alpha (Cronbach, 1951) has been calculated. For the scales of personal innovativeness, perceived usefulness and user satisfaction the alpha was satisfactory without dropping any items of the original scale. From the user interface scale the item The computerized instruction provided by Moodle is clear had to be dropped to achieve a satisfactory alpha. The alpha for the personal innovativeness scale was 0.8 , for the user interface scale 0.71 , for the perceived usefulness scale 0.844 , and for the user satisfaction scale 0.78 .

Using the Kruskal-Wallis test (Kruskal and Wallis, 1952) is has been determined that only on the user interface scale there is a difference between the factors. Using Dunn's test (Dunn, 1964) it has been determined that factor 1, of the following Qanalysis, differs significantly from the other two factors on the user interface scale. Additionally, the participants had to select one of their courses for the context of this study and were asked about the number of students in the chosen course, how the assessment of the students took place, whether it was a lecture or a seminar, and whether they managed their course alone or together with someone else. All the information gathered using the pre-sorting questionnaire has been used in the factor interpretation.

\section{Post-sorting interview}

After the participant finished sorting the cards a short post-sorting interview has been conducted to inquire about the reasons why the participant sorted which cards to which position. The participants were asked to explain why they sorted which functionalities to the extremes and whether they were missing anything or discovered anything new during the sorting.

\section{Participants}

The participants were sampled from lecturers using the LMS. The selection of the participants in Q-methodology is not random. In this study the participants were sampled from active users of the LMS and had to have at least two semesters of experience in using Moodle and had to have used if for more then uploading files. Data from 21 participants has been collected and the participants came from eight of the 15 faculties. The participants were on average 34 years old and were teaching on average four hours a week. Five of the participants were female and 16 were male. On average the participants rated themselves at 3.76 on the personal innovativeness scale, at 3.85 on the user interface scale, at 4.32 on the perceived usefulness scale and at 4.41 on user satisfaction scale. The participants had on average 5.4 years experience with Moodle. 12 of the participants had experience with another LMS, which in the most cases was StudIP. The courses they chose as a reference for this study had on average 106 students with the median being at 25 students. The smallest course consisted of 12 students and the biggest course of 700 students. Most of the participants managed their course alone and gave a seminar in which the student performance was determined using an assignment. During the data 
collection it has been recorded how many cards the participants sorted into the three categories of unimportant, neutral and important before sorting the cards along the distribution. This information has been used to aid the factor interpretation. Of the most interest are the cards the participants rated as important for their course. On average these were 13.71 cards.

\section{Procedure}

The data collection took place in person with a data collection form on paper and a printed Q-set. The language used during the data collection was German. In the first part of the data collection the participants filled in the pre-sorting questionnaire by themselves while the interviewer was preparing the Q-sort. Once the participant finished the pre-sorting questionnaire the participant was asked to choose a reference course for the Q-sort. The Q-sort started with the participant sorting the cards into the three categories of unimportant, neutral and important for their course. Following this the participant sorted the cards along the provided distribution. Once the sorting was completed the interviewer inquired about the sorting reasons in the post-sorting interview. Upon entering the collected data into the computer for analysis the data was anonymised.

\section{Q-sorts analysis}

The analysis of the Q-sorts has been conducted using the qmethod $\mathrm{R}$ package (Zabala, 2014) and using PCA three components were extracted. The number of components to extract has been determined based on the Kaiser-Guttmann criterion (Guttman, 1954; Kaiser, 1960; Kaiser, 1970), parallel analysis (Horn, 1965) as well as scree test optimal coordinates and the acceleration factor (Raîche et al., 2013), which are non-graphical versions of the scree test (Cattell, 1966), see figure 2.

The analysis of the Q-sorts consisted of two main parts. The first part is to apply a multivariate data reduction technique, in this case PCA. At first a correlation matrix of the Q-sorts is created which is reduced to components by PCA. This is followed by the rotation of the data, in this study varimax rotation has been used. The second part of analysing the Q-sorts is unique to the Q-methodology. It consists of the following three steps: (1) flagging the Q-sorts for each component, (2) calculating the scores (z-scores and factor scores) for the items and (3) determining which of the items are consensus items and which items are distinguishing for the components (Zabala, 2014).

The purpose of flagging the Q-sorts is to select the Q-sorts which define the components. This can be done either manually or automatically. In this study the flagging has been done automatically. The criteria for flagging were that the loading should be significantly high with a significance threshold for a p-value of $<.05$ and that the square loading for a component should be higher than for any of the other components (Brown, 1980). Once the flagging is completed the z-scores can be calculated which show the relationship between the items and the components. The factor scores are based on the z-scores. This is followed by determining the consensus and distinguishing items by comparing the components based on the standard error of differences (Zabala, 2014).

Together the three components explain $59.45 \%$ of the study variance. 18 of the 21 
Figure 2 Non Graphical Solutions to the Scree Test based on Raîche et al. (2013)

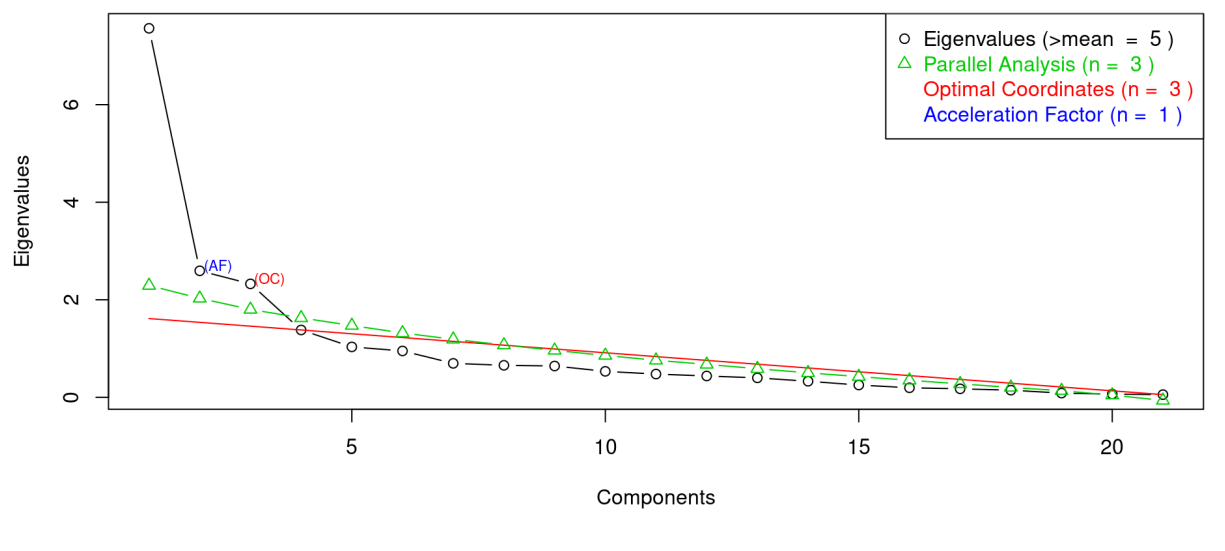

Q-sorts loaded on one of the three components, or factors as they are usually called in the literature (Zabala, 2014). The outcome of this analysis is the number of factors which each represent a theoretical point of view. These are theoretical Q-sorts based on the factor scores. Thus they are based on a number of Q-sorts that loaded significantly on a factor because they exhibited a similar sorting pattern. Table 1 shows the factor scores for each item and factor.

\section{Interpretation}

The interpretation of the factors forms the results. The first step in the interpretation of the factors was to determine how many cards were sorted as important per factor. Based on this information it could be described which functionalities were of importance for each factor and which were unimportant. In the next step the information gathered during the post-sorting interviews was used to interpreted why functionalities were important to the participants based on their sorting reasons. Especially the participants reasons for sorting the distinguishing items were key to interpreting the factors. The pre-sorting questionnaire, including the demographic data, was used to provide background information about the participants per factor.

\section{Results}

The results section covers the consensus items as well as the three extracted factors in detail.

\section{Consensus}

Of the 41 items that could be sorted five got a similar score in all three factors. Two of the five were rated by the participants as important and these have high scores within the factors. These two items are the announcements $(+4,+2,+3)$ and the forum ( +3 in all factors). It is important to note that the announcements functionality is an appropriation of the forum in which only instructors can post and all students enrolled in the course can read this post in the course and will receive the post via email. Consensus items that were not important are the feedback $(+1$, 
$0,+1)$ and calendar $(-1,-2,-2$,$) functions as well as the use case of recording grades$ in a database.

Reasons stated why the forum ( +3 in all factors) and the announcements $(+4$, $+2,+3)$ are sorted so high are that these are an easy way for the instructors to communicate with the students as all in the course enrolled students can be reached and it is easier than sending out emails. Furthermore a full record of the conversations is available for the instructors as well as for the students.

\section{Factor 1 - Convenience}

Factor 1 has an eigenvalue of 6.04 and explains $28.77 \%$ of the study variance. Nine participants load on this factor. They are on average 31.88 years old and three of them are female and six male. They were teaching on average three hours a week and had 5.88 years of experience with Moodle. In comparison with the other two factors the participants who form this factor are the most satisfied with the user interface. The reference courses chosen by the participants had on average 39.77 enrolled students with the median being at 22 enrolled students. The smallest course consisted of 12 students and the biggest of 150 students. Most of the participants

Table 1 Factor scores for each item and factor

\begin{tabular}{|c|c|c|c|}
\hline Item & Factor 1 & Factor 2 & Factor 3 \\
\hline workshop & -2 & -3 & +5 \\
\hline badges & -4 & +4 & -1 \\
\hline database & +2 & -2 & +4 \\
\hline portfolio & -1 & -1 & +4 \\
\hline completion-tracking & -4 & +2 & 0 \\
\hline assignment-in-database & +2 & -4 & +2 \\
\hline lesson & -2 & +4 & -1 \\
\hline rights-management-in-course & +1 & +1 & -4 \\
\hline quiz & 0 & +5 & 0 \\
\hline chat & -5 & 0 & -5 \\
\hline appointment-choice & -3 & -3 & +1 \\
\hline file & +5 & +3 & +1 \\
\hline assignment & +4 & +2 & -1 \\
\hline literature-database & -1 & -1 & +2 \\
\hline learning-diary & -2 & -5 & +1 \\
\hline groups & +3 & 0 & 0 \\
\hline fair-allocation & 0 & -2 & -4 \\
\hline topic-choice & 0 & -3 & -2 \\
\hline grades & -1 & +1 & -1 \\
\hline signup-database & +2 & -2 & -1 \\
\hline wiki & +0 & -1 & +2 \\
\hline group-choice & +2 & -1 & -1 \\
\hline lecture-recordings & +1 & 0 & -2 \\
\hline conditional-availability & 0 & +2 & 0 \\
\hline book & -3 & 0 & -2 \\
\hline glossary & -2 & +1 & +1 \\
\hline questionnaire & 0 & -1 & +2 \\
\hline visibility & +3 & +3 & 0 \\
\hline embed-page & -2 & 0 & -3 \\
\hline library-resources & -1 & -2 & -3 \\
\hline link-sciebo & -1 & 0 & -3 \\
\hline choice & +1 & -1 & 0 \\
\hline folder & +1 & +1 & +2 \\
\hline page & 0 & +1 & 0 \\
\hline label & +1 & +1 & +3 \\
\hline url & +2 & +2 & +1 \\
\hline feedback & +1 & 0 & +1 \\
\hline grades-in-database & -3 & -4 & -2 \\
\hline announcements & +4 & +2 & +3 \\
\hline forum & +3 & +3 & +3 \\
\hline calendar & -1 & -2 & -2 \\
\hline
\end{tabular}


in this factor managed their course alone and gave a seminar in which the students performance was determined using an assignment. The participants sorted an average of 22 cards as unimportant, 6.11 as neutral and 12.88 as important.

Excluding consensus items the items rated as important in this factor are the file upload $(+5)$, assignments $(+4)$, sorting students into groups $(+3)$, activity visibility $(+3)$, creating links $(+2)$, signing up for something in a database $(+2)$, choosing a group via a poll $(+2)$, the database $(+2)$, handing in files using the database $(+2)$ as well as the label function $(+1)$ and the rights management with the course $(+1)$. Of these items the sorting students into groups $(+3)$, the signing up in a database $(+2)$ and the choosing a group via a poll $(+2)$ items are distinguishing for this factor and these were sorted higher than in the other two factors. The least important for this factor are the completion tracking (-4), the badges (-4) and the chat (-5).

Reasons stated by the participants were that the file upload $(+5)$ is the basis for the whole course to provide the basic study material but also additional material which is also what links $(+2)$ are being used for. The reason that the assignment $(+4)$ was sorted so high is that it makes recording the performance easier because all the assignments for the whole course are already in one place. Being able to determine when course activities are visible to the students was important $(+3)$ for the participants because it allows them to prepare the course in advance and only make the activities visible to the students once they become relevant. The function of being able to sort students into groups $(+3)$ was rated high because it can influence all parts of the course. Reasons stated why the chat (-5) was sorted so low were that the implementation in Moodle is not good.

Five of the participants in this factor stated that they were missing a functionality that they used in their course or would have liked to use. Functionalities that the participants were missing was a video upload, live polls and the possibility to have group based folders. Of these the video upload would have been the most important. Functionalities that would have been nice to have are a Dropbox integration and outside of Moodle Blogger, WordPress, Socrative, Padlet and Tricider have been used in the context of the chosen courses. Furthermore six of the participants in this factor stated to have discovered new and for them interesting functionalities during the sorting process. These were the lecture recordings, the wiki, the glossary, the literature database, the feedback function, the quiz, the questionnaire function, signing up for a consultation hour using a poll, the fair allocation, the portfolio and the possibility to see an overview of the grades.

Factor 1 represents the convenience an LMS offers to instructors. The participants in this factor perceive the LMS as useful and are satisfied with it. What is most important is what makes their work easier, like having all files related to the course in one place as well as all student submissions. Furthermore relevant to them is being able to prepare everything in advance and to not have to put too much effort into their course during the semester. It is important to structure the course well so that content can be made available week by week.

\section{Factor 2 - Tracking progress}

Factor 2 has an eigenvalue of 3.77 and explains $17.96 \%$ of the study variance. Five participants load on this factor. They are on average 36.6 years old and all five 
are male. They were teaching on average 2.6 hours a week and had 4.35 years of experience with Moodle and most of them had no experience with another LMS. The reference courses chosen by the participants had on average 190.4 enrolled students with the median being at 127 enrolled students. The smallest course consisted of 25 students and the biggest of 600 students. Most of the participants in this factor managed their course alone and gave a lecture in which the student performance was determined using an exam. The participants sorted an average of 23.8 cards as unimportant, 4.2 as neutral and 13 as important.

Excluding consensus items the items rated as important in this factor are the quiz $(+5)$, badges $(+4)$, the file upload $(+3)$, the possibility to create lessons $(+4)$, activity visibility $(+3)$, assignments $(+2)$, completion tracking $(+2)$, conditional availability $(+2)$, creating links $(+2)$, being able to see overall grades $(+1)$ and the page $(+1)$. Of these items the conditional availability $(+2)$ as well as being able to see overall grades $(+1)$ are distinguishing for this factor and these were sorted higher than in the other two factors. The least important for this factor is the handing in of files in a database (-4), recording grades in a database (-4) and the learning diary (-5).

Reasons stated why the quiz (+5) was sorted so high are that the quiz can be used by the students before the class and then the class can be used to focus on topics that the students did not understand that well yet. The reasoning for sorting the badges $(+4)$ so high is similar as it can be used by the students to track their progress and is perceived as motivating. The assignments $(+2)$ on the other hand are also used to track the students progress by having them do frequent assignments. Also directly related to the student performance is the lesson $(+4)$ as it can be used to get all students to the same level. Reasons stated for sorting the recording grades in a database (-4) and the learning diary (-5) so low was that the participants just did not see a use case for these.

Three of the participants in this factor stated that they were missing a functionality that they used in their course or would have liked to use. Functionalities that the participants were missing was the active quiz for quizzes during lectures, a XPblock which is similar to the badges, rating programming code, an integration with Linda.com to include their learning videos and interactive HTML5 activities. Of these the active quizzes, the rating of programming code and the HTML5 activities were the most important. Furthermore one of the participants in this factor stated to have discovered a new and interesting functionally during the sorting process which was being able to include library resources in the course.

The main characteristic of factor 2 is that it is focused on tracking the students progress to adjust the teaching for it. This is done before the lectures by using quizzes or lessons in order to adjust the following lecture to the students needs. Tracking the students progress after the lectures or in between lectures is being done using frequent assignments that the students then hand in using the assignment function. With the grades function the instructors then can see an overview of the grades. What can be helpful and motivating for the students is using the badges or an $X P$-block which shows the students their progress and which is received well by the students according to the participants. Of the most importance for this factor is knowing how well the students are doing by frequently measuring it. 


\section{Factor 3 - Student interaction}

Factor 3 has an eigenvalue 2.67 and explains $12.73 \%$ of the study variance. Four participants load on this factor. They are on average 34.25 years old and two of them are female and two male. They were teaching on average five hours a week and had 6.37 years of experience with Moodle and half of them had experience with another LMS. The reference courses chosen by the participants had on average 186.75 enrolled students with the median being at 16.5. The smallest course consisted of 14 students and the biggest of 700 students. Most of the participants in this factor managed their course alone and gave a seminar in which the student performance was determined using an assignment. The participants sorted an average of 21.5 cards as unimportant, 4.5 as neutral and 15 as important.

Excluding consensus items the items rated as important in this factor are the workshop $(+5)$, the portfolio $(+4)$, the database $(+4)$, the label $(+3)$, providing a literature overview in a database $(+2)$, the folder $(+2)$, the wiki $(+2)$, handing in files in a database $(+2)$, the questionnaire $(+2)$, signing up for a consultation hour using a poll $(+1)$, creating links $(+1)$, the file upload $(+1)$, and the glossary $(+1)$. Of these items the workshop $(+5)$, the portfolio $(+4)$, the literature overview in a database $(+2)$, the folder $(+2)$, the wiki $(+2)$ and the signing up for a consultation hour using a poll $(+1)$ are distinguishing for this factor and these were sorted higher than in the other two factors. The least important for this factor is the fair allocation $(-4)$, the rights management within the course (-4) and the chat (-5).

The workshop $(+5)$ was rated highly by the participants as it provides them with an easy and well structured way to let students give feedback to each other. The portfolio $(+4)$ and the database $(+4)$ was used by the instructors to get feedback from the students and to have them reflect on their learning progress. The rights management in the course (-4) and the chat (-5) were sorted so low because the participants did not see a use case for these.

Three of the participants in this factor stated that they were missing a functionality that they used in their course or would have liked to use. Functionalities that the participants were missing was the possibility to have a modern portfolio, individualised project management in the course, being able to annotate videos and to send out automated emails. Of these the automated emails would have been the most important. Etherpad, WordPress and Adobe Connect have been used in the context of the chosen courses. Furthermore three of the participants in this factor stated to have discovered new and for them interesting functionalities during the sorting process. These were the calendar and being able to make activities visible to the students at a predefined time.

The high interaction among the students and between students and instructors is the main characteristic of factor 3. Students providing feedback to each other is what everything is about in this factor. Improving ones work based on the feedback from other students and the instructor is the goal which is achieved by an high interaction among the students and between the students and the instructor.

\section{Factor comparison}

The main difference between the factors is that while factor 1 focusses on the productivity of the instructors, factor 2 and factor 3 represent use cases for which the 


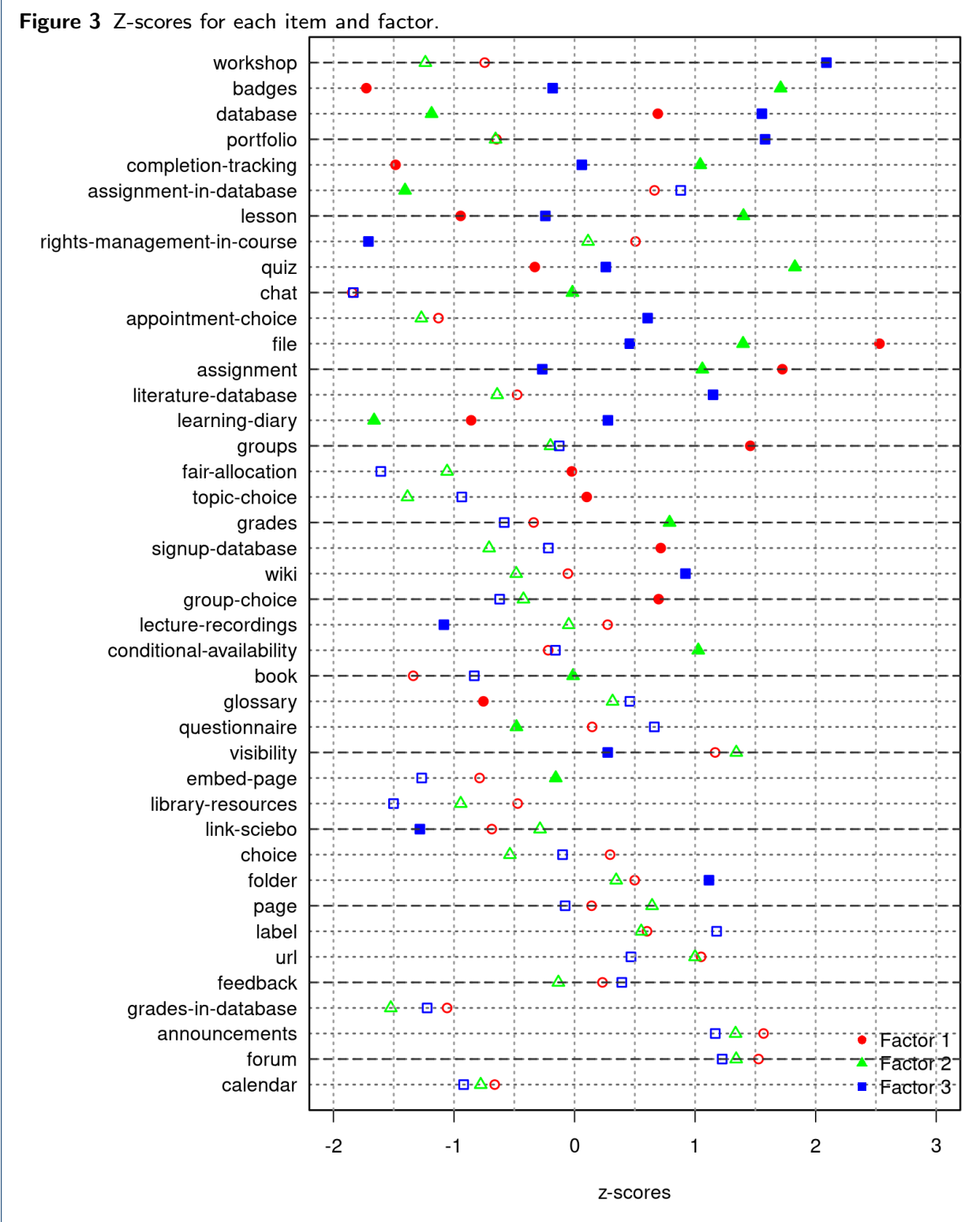

usage of the LMS is essential as those could not have been implemented otherwise. In factor 2 and factor 3 the course is part of the learning process for the students with elements such as quizzes before a class, handing in assignments or giving feedback to each other. In both factors the teaching is adjusted based on the students' needs with the difference being that in factor 2 it is done in preparation for an exam and by measuring the students progress while in factor 3 it is done in the process of working on an assignment by constantly providing the students with feedback. Figure 3 shows all functionalities sorted by agreement. The functionalities the factors agree upon the most are at the bottom and the functionalities the factors disagree upon the most are at the top. Functionalities which are distinguishing for a factor are plotted using filled symbols while not distinguishing functionalities are plotted using an empty symbol. Thus figure 3 shows that what all factors agree upon are 
the functionalities described in the consensus section, e.g. the announcements and the forum. What the factors disagree upon the most are also the functionalities which are important for the factors, e.g. the workshop, the quiz or the assignment.

\section{Discussion}

The main focus of this study was on the appropriation of instructors using an LMS to create a course. Functionalities which are important to the instructors are most of all the forum and the possibility of writing announcements using the forum. Patterns that emerged in the perception of importance are that there are three factors representing three different points of view. These are, the first factor which is focussed on the convenience offered by the LMS and how it can make the work of the instructors easier, the second factor which is focused on tracking the students progress online as well as during exercise meetings using various functionalities, and the third factor which is about interaction among the students and between students and instructors.

In comparison to Whitmer (2016) who analyzed patterns in the course design of Blackboard courses based on usage frequency it could be stated that factor 1 of this study corresponds to the complementary archetype as a lot of content is provided and the communication is mainly from the instructor to the student. Factor 2 could correspond to the evaluative archetype as it is also focused on determining the students progress by measuring it. Factor 3 could correspond to the social archetype as the interaction among the students is high as well as between the instructor and the students. No corresponding factor for the archetypes supplemental and holistic exist with a possible explanation being that the supplemental archetype would correspond to the participants excluded via the participant selection criteria and the holistic archetype might be too small to emerge as a factor in this dataset.

Furthermore, the consensus results are in line with Lonn and Teasley (2009) who stated that the most common benefit of an LMS for the instructors is that it allows them to improve their communication with their students. It has been stated that there are two groups of instructors among those who use the LMS, one group that focusses on information transfer and one group that focuses on student learning (Schoonenboom, 2014). Applied to the context of this study it can stated that the participants who form factor 1 can be grouped as belonging to the group focused on information transfer while the participants who form factor 2 and factor 3 can be grouped as being focused on student learning.

Limitations of this study are that most of the participants chose a reference course with a rather small number of enrolled students and only two of the participants chose reference courses with multiple hundreds of students. Including more participants with courses with multiple hundreds of students might have led to different results and maybe even an additional factor. Another point of concern is that while sorting the items into the three categories of unimportant, neutral and important, before sorting the cards along the distribution, most of the participants sorted more cards as unimportant than as important. Often they stated that sorting the unimportant functionalities along the distribution was more difficult for them. The sorting of the cards to the important side of the distribution might be more reliable than the sorting of the cards to the unimportant side. 
Suggestions for future research are (1) to use the results from this study to analyse the usage frequency by factor in the LMS for a better comparison with Whitmer (2016), (2) to compare the perception of the instructors with the perception of the students to study whether what is perceived as important by the instructors is also perceived as important by the students and (3) to apply the research design from this study at different universities with different LMSs and different teaching concepts to compare the results and based on these (4) compare which course designs work better in a distance learning setting and which course designs work better in a setting in which the LMS is used to support traditional teaching.

Practical implications of this study could be to create course templates to be used by instructors upon creating a new course in the LMS and to use these as examples in teaching instructors how to make use of the LMS.

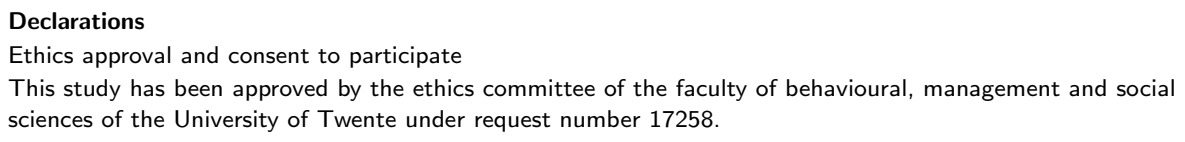


References

Agarwal, R. and Prasad, J. (1998). A Conceptual and Operational Definition of Personal Innovativeness in the Domain of Information Technology. Information Systems Research, 9(2):204-215. doi:10.1287/isre.9.2.204.

Al-Busaidi, K. A. and Al-Shihi, H. (2012). Key factors to instructors' satisfaction of learning management systems in blended learning. Journal of Computing in Higher Education, 24(1):18-39. doi:10.1007/s12528-011-9051-x.

Block, J. (2008). Q-sort methodology. In The Q-sort in character appraisal: Encoding subjective impressions of persons quantitatively., chapter 5, pages 45-53. American Psychological Association, Washington. doi:10.1037/11748-005

Brown, S. R. (1980). Political Subjectivity: Applications of Q Methodology in Political Science. Yale University Press, New Haven.

Brown, S. R. (2004). Q Methodology. In Lewis-Beck, M. S., Bryman, A., and Liao, T. F., editors, The SAGE Encyclopedia of Social Science Research Methods, pages 887-888. Sage Publications, Inc., Thousand Oaks. doi:10.4135/9781412950589.n938.

Cattell, R. B. (1966). The Scree Test For The Number Of Factors. Multivariate Behavioral Research, 1(2):245-276 doi:10.1207/s15327906mbr0102_10.

Cho, V., Cheng, T. E., and Lai, W. J. (2009). The role of perceived user-interface design in continued usage intention of self-paced e-learning tools. Computers \& Education, 53(2):216-227. doi:10.1016/j.compedu.2009.01.014.

Coxon, A. P. M. (2004). Sorting. In Lewis-Beck, M. S., Bryman, A., and Liao, T. F., editors, The SAGE Encyclopedia of Social Science Research Methods, page 1049. Sage Publications, Inc., Thousand Oaks. doi:10.4135/9781412950589.n938.

Cronbach, L. J. (1951). Coefficient alpha and the internal structure of tests. Psychometrika, 16(3):297-334 doi:10.1007/BF02310555

Davis, F. D. (1989). Perceived Usefulness, Perceived Ease of Use, and User Acceptance of Information Technology. MIS Quarterly, 13(3):319. doi:10.2307/249008

Dix, A. (2007). Designing for Appropriation. Proceedings of the 21st BCS HCl Group Conference, 2(September):2-5. doi:10.1361/asmhba0003455

Dourish, P. (2003). The Appropriation of Interactive Technologies: Some Lessons from Placeless Documents. Computer Supported Cooperative Work (CSCW), 12(4):465-490. doi:10.1023/A:1026149119426.

Dunn, O. J. (1964). Multiple Comparisons Using Rank Sums. Technometrics, 6(3):241-252. doi:10.1080/00401706.1964.10490181.

Ebbert, D. (2017a). Patterns in the appropriation of a learning management system by instructors based on Q-methodology: Analysis script [Software]. doi:10.5281/zenodo.847217.

Ebbert, D. (2017b). Patterns in the appropriation of a learning management system by instructors based on Q-methodology: Dataset [Data files and code book]. doi:10.5281/zenodo.835415.

Green, K. C. (2013). The 2013 Campus Computing Survey. Technical report, The Campus Computing Project. Retrieved from http://www.campuscomputing.net/item/2013-campus-computing-survey-0.

Guttman, L. (1954). Some necessary conditions for common-factor analysis. Psychometrika, 19(2):149-161. doi:10.1007/BF02289162.

Hew, T.-S. and Syed Abdul Kadir, S. L. (2016). Predicting instructional effectiveness of cloud-based virtual learning environment. Industrial Management \& Data Systems, 116(8):1557-1584. doi:10.1108/IMDS-11-2015-0475.

Horn, J. L. (1965). A rationale and test for the number of factors in factor analysis. Psychometrika, 30(2):179-185 doi:10.1007/BF02289447

Huysman, M., Steinfield, C., Jang, C. Y., David, K., 'T Veld, M. H. I., Poot, J., and Mulder, I. (2003). Virtual teams and the appropriation of communication technology: Exploring the concept of media stickiness. Computer Supported Cooperative Work: CSCW: An International Journal, 12(4):411-436. doi:10.1023/A:1026145017609.

Kaiser, H. F. (1960). The Application of Electronic Computers to Factor Analysis. Educational and Psychological Measurement, 20(1):141-151. doi:10.1177/001316446002000116.

Kaiser, H. F. (1970). A second generation little jiffy. Psychometrika, 35(4):401-415. doi:10.1007/BF02291817.

Kruskal, W. H. and Wallis, W. A. (1952). Use of Ranks in One-Criterion Variance Analysis. Journal of the American Statistical Association, 47(260):583-621. doi:10.1080/01621459.1952.10483441.

Lonn, S. and Teasley, S. D. (2009). Saving time or innovating practice: Investigating perceptions and uses of Learning Management Systems. Computers \& Education, 53(3):686-694. doi:10.1016/j.compedu.2009.04.008.

MacLean, A., Carter, K., Lövstrand, L., and Moran, T. (1990). User-tailorable systems: pressing the issues with buttons. In Proceedings of the SIGCHI conference on Human factors in computing systems Empowering people - CHI '90, number April, pages 175-182, New York, New York, USA. ACM Press. doi:10.1145/97243.97271.

McGill, T. J. and Klobas, J. E. (2009). A task-technology fit view of learning management system impact. Computers and Education, 52(2):496-508. doi:10.1016/j.compedu.2008.10.002.

Motaghian, H. Hassanzadeh, A and Moghadam, D. K. (2013). Factors affecting university instructors' adoption of web-based learning systems: Case study of Iran. Computers \& Education, 61:158-167. doi:10.1016/j.compedu.2012.09.016.

Mouakket, S. and Bettayeb, A. M. (2015). Investigating the factors influencing continuance usage intention of Learning management systems by university instructors. International Journal of Web Information Systems, 11(4):491-509. doi:10.1108/IJWIS-03-2015-0008.

Raîche, G., Walls, T. A., Magis, D., Riopel, M., and Blais, J.-G. (2013). Non-Graphical Solutions for Cattell's Scree Test. Methodology, 9(1):23-29. doi:10.1027/1614-2241/a000051.

Raman, A. and Don, Y. (2013). Preservice Teachers' Acceptance of Learning Management Software: An Application of the UTAUT2 Model. International Education Studies, 6(7):157-164. doi:10.5539/ies.v6n7p157. 
Ritzhaupt, A. D. and Martin, F. (2014). Development and validation of the educational technologist multimedia competency survey. Educational Technology Research and Development, 62(1):13-33. doi: $10.1007 / \mathrm{s} 11423-013-9325-2$

Salovaara, A. (2007). Appropriation of a MMS-based comic creator. In Proceedings of the SIGCHI conference on Human factors in computing systems - CHI '07, page 1117, New York, New York, USA. ACM Press. doi:10.1145/1240624.1240794.

Salovaara, A., Helfenstein, S., and Oulasvirta, A. (2011). Everyday appropriations of information technology: A study of creative uses of digital cameras. Journal of the American Society for Information Science and Technology, 62(12):2347-2363. doi:10.1002/asi.21643.

Salovaara, A. and Tamminen, S. (2009). Acceptance or Appropriation? A Design-Oriented Critique of Technology Acceptance Models. In Future Interaction Design II, pages 157-173. Springer London, London. doi:10.1007/978-1-84800-385-9_8.

Schoonenboom, J. (2014). Using an adapted, task-level technology acceptance model to explain why instructors in higher education intend to use some learning management system tools more than others. Computers and Education, 71:247-256. doi:10.1016/j.compedu.2013.09.016.

Sinclair, J. and Aho, A.-M. (2017). Experts on super innovators: understanding staff adoption of learning management systems. Higher Education Research \& Development, 0(0):1-15. doi:10.1080/07294360.2017.1342609.

S $\varnothing$ reb $\varnothing$, A. M. and S $\varnothing$ reb $\varnothing, \varnothing$. (2008). Understanding E-Learning Satisfaction in the Context of University Teachers World Academy of Science, Engineering and Technology, 46:72-75.

Stephenson, W. (1953). The study of behavior; Q-technique and its methodology. University of Chicago Press, Chicago.

Šumak, B., Polančič, G., and Heričko, M. (2010). An Empirical Study of Virtual Learning Environment Adoption Using UTAUT. In 2010 Second International Conference on Mobile, Hybrid, and On-Line Learning, pages 17-22. IEEE. doi:10.1109/eLmL.2010.11.

ten Klooster, P. M., Visser, M., and de Jong, M. D. T. (2008). Comparing two image research instruments: The Q-sort method versus the Likert attitude questionnaire. Food Quality and Preference, 19(5):511-518. doi:10.1016/j.foodqual.2008.02.007.

Torrisi-Steele, G. and Drew, S. (2013). The literature landscape of blended learning in higher education: the need for better understanding of academic blended practice. International Journal for Academic Development 18(4):371-383. doi:10.1080/1360144X.2013.786720.

Venkatesh, V., Morris, M. G., Davis, G. B., and Davis, F. D. (2003). User Acceptance of Information Technology: Toward a Unified View. MIS Quarterly, 27(3):425-478.

Venkatesh, V., Thong, J. Y. L., and Xu, X. (2012). Consumer Acceptance and Use of Information Technology: Extending the Unified Theory of Acceptance and Use of Technology. MIS Quarterly, 36(1):157-178.

Watts, S. and Stenner, P. (2012). Doing Q Methodological Research. Sage Publications, Inc., Thousand Oaks, 1 edition.

Weick, K. E. (1990). Technology as equivoque: Sensemaking in new technologies. In Technology and organizations, pages 1-44. Jossey-Bass, San Francisco, CA, US

Whitmer, J. (2016). Patterns in Course Design: How instructors ACTUALLY use the LMS. Retrieved June 18 2017, from http://blog.blackboard.com/patterns-in-course-design-how-instructors-actually-use-the-Ims/.

Williams, R., Stewart, J., and Slack, R. (2005). Social Learning in Technological Innovation: Experimenting with Information and Communication Technologies. Edward Elgar Publishing.

Yueh, H.-P. and Hsu, S. (2008). Designing a learning management system to support instruction. Communications of the ACM, 51(4):59-63. doi:10.1145/1330311.1330324.

Zabala, A. (2014). qmethod: A Package to Explore Human Perspectives Using Q Methodology. The $R$ Journal, 6(2):163-173

Appendix A: Q-set

\begin{tabular}{|c|c|c|}
\hline Handle & Name & Description \\
\hline workshop & Workshop & $\begin{array}{l}\text { In a workshop the participants hand } \\
\text { in assignments and peer grade these. }\end{array}$ \\
\hline badges & Badges & $\begin{array}{l}\text { Badges are a way to document learn- } \\
\text { ing progress. }\end{array}$ \\
\hline database & Database & $\begin{array}{l}\text { In a database information can be col- } \\
\text { lected together with the students in a } \\
\text { course. For this a information struc- } \\
\text { ture can be defined. }\end{array}$ \\
\hline portfolio & Portfolio & $\begin{array}{l}\text { Over the course of the semester the } \\
\text { students create a portfolio using a } \\
\text { database or a forum. }\end{array}$ \\
\hline completion-tracking & Completion tracking & $\begin{array}{l}\text { For activities and materials you can } \\
\text { define when they count as completed, } \\
\text { e.g. upon clicking on something or } \\
\text { uploading a file. }\end{array}$ \\
\hline assignment-in-database & Upload in Database & $\begin{array}{l}\text { Students hand in an assignment via } \\
\text { a file upload in a database. }\end{array}$ \\
\hline
\end{tabular}




\section{File - Upload}

Assignment

Literature database

Learning diary

Theme choice

Grades

Registration

Groupchoice

Lecture recordings

Conditional availability

Book
Lessons are a collection of pages and links between these pages. This can used to guide the participants from page to page to create for example a self learning unit.

Within a course instructors can give more rights to participants for certain activities.

You can add quizzes to your course. You can determine the course of these quizzes and create test questions.

In a chat learning materials or assignments can be discussed by small groups.

The students sign up for a consultation hour using a poll.

If you already have learning material as a file, you can upload it directly. Assigments can be created that can be solved either online or offline. Submitting the solution can take place in form of a text entry of file upload. You can provided feedback and the correct solution.

The database can be used to create an overview of the literature to be read. This can also be created by the course participants.

Over the course of the semester the students create a learning diary using a database or forum.

Instructors can sort participants into groups for the whole course or certain activities.

This Module lets you add an activity to courses, in which users can rate choices. You may then distribute the users fairly to the choices by maximising overall 'hapiness' in terms of ratings. This may be an alternative to the choice activity or first-come-firstserved.

The students choose of theme for a homework or other assignment using a poll. The assignment is done manually is first-come-first-serve.

As an instructor you can see the participants grades for activities, categories and calculate overall grades. Students sign up for something (e.g. a seminar or a exam) using a choice in a database.

A wiki is a collection of linked pages. In a shared wiki everybody can see and edit all pages.

The students can choose a group using a poll.

Lecture recordings provide the students with the possibility to rewatch lectures afterwards to go through difficult parts or to prepare for exams. Conditional availability enables lecturers to link the availability of activities or files to conditions.

Instead of having to scroll through long text, you can split learning materials into short pages of a book. This can be supplemented with graphics and multimedia elements. 


\begin{tabular}{|c|c|}
\hline glossary & Glossary \\
\hline questionnaire & Questionnaire \\
\hline visibility & Visibility \\
\hline embed-page & External HTML-Content \\
\hline library-resources & Electronic library resources \\
\hline link-sciebo & Link to a file sharing service \\
\hline choice & Choice \\
\hline folder & Folder \\
\hline page & Page \\
\hline label & Label \\
\hline url & Link / URL \\
\hline feedback & Feedback \\
\hline grades-in-database & Performance record \\
\hline announcements & Announcements \\
\hline forum & Forum \\
\hline & Calendar \\
\hline
\end{tabular}

Using a glossary you can create a dictionary or a FAQ list. Glossaries can be created by instructors or students The questionnaire modul can be used to create surveys that can be completed by the participants.

Activities can be visible or hidden. This way activities can be created that are not immediately visible for the participants. Changing the visibility can be done manually or time based.

Using a text page external HTMLcontent can be shown in a course e.g. a YouTube video.

Electronic library resources can be used within a course to provide students with papers and small parts of books in digital form

Using a link to files uploaded to an external file sharing service.

With the choice function you can ask a question in the course with a predefined set of answers.

If you have a greater number of files that you want to have in your course, you can create a folder for it. This can be used to gather files per topic.

On a page you can create learning content for the participants with an editor.

A label is shown on the course page e.g. as a heading, a hint or as part of the course orientation.

With a URL you can redirect your participants to other pages on the in ternet.

With the feedback modul you can create surveys or evaluation forms using multiple question types.

The performance of the students is being recorded using a database.

Announcements are made via a special forum. It is intended to send messages to all course members.

You can create a forum to enable your students to discuss a topic within a course.

In a calendar you can make various entries, like deadlines or exams. 